\title{
Cetuximab: its unique place in head and neck cancer treatment
}

\author{
This article was published in the following Dove Press journal: \\ Biologics:Targets and Therapy \\ 12 April 2013 \\ Number of times this article has been viewed
}

\section{Pol Specenier Jan B Vermorken}

Department of Medical Oncology, Antwerp University Hospital, Edegem, Belgium
Correspondence: Pol Specenier; Jan B Vermorken Department of Medical Oncology, Antwerp University Hospital, Wilrijkstraat, 10, 2650 Edegem, Belgium

$\mathrm{Tel}+323$ 82I 40I4

Email pol.specenier@uza.be; janb.vermorken@uza.be

\begin{abstract}
Head and neck cancer is the sixth most common cancer worldwide. At present, globally about 650,000 new cases of squamous cell carcinoma of the head and neck (SCCHN) are diagnosed each year. The epidermal growth factor receptor (EGFR) is almost invariably expressed in SCCHN. Overexpression of the EGFR is a strong and independent unfavorable prognostic factor in SCCHN. Cetuximab is a chimeric monoclonal antibody, which binds with high affinity to the extracellular domain of the human EGFR, blocking ligand binding, resulting in inhibition of the receptor function. It also targets cytotoxic immune effector cells towards EGFR-expressing tumor cells (antibody dependent cell-mediated cytotoxicity). The addition of cetuximab to radiotherapy (RT) improves locoregional control and survival when compared to RT alone. The addition of cetuximab to platinum-based chemoradiation (CRT) is feasible but does not lead to an improved outcome. Cetuximab plus RT has never been compared prospectively to CRT, which therefore remains the standard treatment for patients with locoregionally advanced SCCHN for whom surgery is not considered the optimal treatment, provided they can tolerate CRT. The addition of cetuximab to platinum-based chemotherapy prolongs survival in patients with recurrent or metastatic SCCHN. The combination of a platinum-based regimen and cetuximab should be considered as the standard first line regimen for patients who can tolerate this treatment.
\end{abstract}

Keywords: SCCHN, cetuximab, recurrent metastatic, locoregionally advanced, chemoradiation

\section{Introduction to the management issues in the treatment of head and neck cancer}

More than $90 \%$ of head and neck cancers are of squamous cell histology and originate in the lip, oral cavity, oropharynx, nasopharynx, hypopharynx, and larynx. ${ }^{1}$

Head and neck cancer is the sixth most common cancer worldwide. At present, globally about 650,000 new cases of squamous cell carcinoma of the head and neck (SCCHN) are diagnosed each year. ${ }^{2}$ SCCHN is most commonly linked to tobacco use. Frequent and heavy consumption of alcohol also increases the risk of SCCHN, and this is particularly so when tobacco and alcohol are used together. ${ }^{3}$ Human papillomavirus is a causal factor in the development of oropharyngeal cancer, even in never-smokers and never-drinkers. ${ }^{4,5}$ Human papillomavirus related tumors have a better prognosis, regardless of which treatment is used. ${ }^{6,7} \mathrm{SCCHN}$ is considered to be the final stage of a multistep process evolving from normal histology over hyperplasia, dysplasia, and carcinoma in situ to invasive carcinoma. ${ }^{8}$ The management of SCCHN is complex and requires a multidisciplinary approach. ${ }^{9,10}$ Single modality treatment with 
surgery or radiotherapy (RT) is generally recommended for the approximately $40 \%$ of patients who present with stage I or II disease. ${ }^{10}$ For patients who present with locoregionally advanced (LA) disease at diagnosis, combined modality therapy is generally recommended. For patients with unresectable disease and for patients with resectable disease in whom organ preservation is desired, the current standard treatment is concurrent cisplatin-based chemoradiation (CRT). ${ }^{10}$ Cisplatin in combination with RT is also indicated postoperatively in patients with high risk pathological findings at surgical resection. ${ }^{10}$ Despite such a combined approach, a significant majority of patients with LA-SCCHN at diagnosis will develop a (loco)regional recurrence or distant metastases. Patients with recurrent or metastatic (R/M) SCCHN have a poor prognosis with a median overall survival (OS) ranging between 6 and 9 months in most studies. ${ }^{11}$

Expression of the epidermal growth factor receptor (EGFR) and its ligand transforming growth factor alpha occurs early in the carcinogenesis of SCCHN. ${ }^{12}$ The EGFR is almost invariably expressed in SCCHN. ${ }^{12,13}$ Overexpression of EGFR is a strong and independent unfavorable prognostic factor in SCCHN. ${ }^{14,15}$

\section{Review of pharmacology, mode of action, and pharmacokinetics of cetuximab}

Thus far, cetuximab (Erbitux ${ }^{\circledR}$; Merck KgaA, Darmstadt, Germany; Imclone Systems, Somerville, NJ, USA) is the only targeted agent which has been approved for the treatment of SCCHN by the regulatory agencies of the United States and Europe. ${ }^{16,17}$ Cetuximab is a chimeric monoclonal antibody of the immunoglobulin G1 class, which binds with high affinity to the extracellular domain of the human EGFR. As the affinity of cetuximab for EGFR is approximately 5 to 10 fold higher than that of the endogenous ligands, it blocks the binding of these ligands resulting in inhibition of the receptor function. Furthermore, cetuximab induces the internalization of EGFR, which can lead to downregulation of EGFR. It also targets cytotoxic immune effector cells towards EGFR expressing tumor cells (antibody dependent cellmediated cytotoxicity). ${ }^{18}$ In vitro exposure of squamous cell carcinoma (SCC) cell lines derived from head and neck cancer patients to cetuximab inhibits proliferation in a time-dependent manner. ${ }^{19}$ Cells accumulate in G1 of the cell cycle. Radiosensitivity is enhanced and radiationinduced apoptosis is amplified both in single dose and fractionated radiation experiments. ${ }^{19}$
Cetuximab and cisplatin induced an (supra)additive effect when combined with irradiation in SCCHN cell lines. ${ }^{20,21}$ Cisplatin and cetuximab in combination resulted in substantial growth inhibition of well-established SCC xenografts when compared with both an untreated control group and animals treated with a single modality. ${ }^{22}$ The population pharmacokinetics of cetuximab have been characterized in 143 R/M-SCCHN patients. ${ }^{23}$ Cetuximab pharmacokinetics were best described by a two-compartment model with Michaelis-Menten-type saturable elimination. Population estimates of the pharmacokinetic parameters were Vmax (maximum elimination rate) $4.38 \mathrm{mg} /$ hour (15.4\%), Km (the concentration with half-maximal elimination rate) $74 \mu \mathrm{g} / \mathrm{mL}$, central compartment volume (V1) 2.83 L (18.6\%), peripheral compartment volume $2.43 \mathrm{~L}$ (56.4\%), and intercompartmental clearance $0.103 \mathrm{~L} /$ hour (97.2\%). Cetuximab pharmacokinetic parameters remained constant during prolonged therapy. Clinical dose adjustments beyond the approved body surface area-based dosing of cetuximab may be warranted in patients with extreme deviations of their actual body weight from ideal body weight. ${ }^{23}$

Baselga et $\mathrm{al}^{24}$ treated 52 patients in three successive Phase I clinical trials of cetuximab as a single dose $(n=13)$, weekly multiple dose $(n=17)$, and weekly multiple dose with cisplatin $(n=22)$. Cetuximab dose levels were 5, 20, 50 , and $100 \mathrm{mg} / \mathrm{m}^{2}$. In the study combining cetuximab with cisplatin, cetuximab was further escalated to 200 and $400 \mathrm{mg} / \mathrm{m}^{2}$. Cisplatin was given at a dose of $60 \mathrm{mg} / \mathrm{m}^{2}$ once every 4 weeks. Cetuximab displayed nonlinear pharmacokinetics, with complete saturation of systemic clearance with cetuximab doses in the range of $200-400 \mathrm{mg} / \mathrm{m}^{2}$. Cetuximab clearance did not change with repeated administration or with coadministration of cisplatin.

Shin et $\mathrm{al}^{25}$ conducted a Phase Ib study with cetuximab in combination with cisplatin in patients with recurrent SCCHN. Twelve patients who had high levels of EGFR expression and tumors easily accessible for repeated biopsies (pre-therapy, 24 hours after first infusion, and 24 hours before third infusion) were entered at three different dose levels of cetuximab (100 mg/ $\mathrm{m}^{2}$ as a loading dose with maintenance doses at $100 \mathrm{mg} / \mathrm{m}^{2}$ weekly; $500 \mathrm{mg} / \mathrm{m}^{2}$ as a loading dose with maintenance doses at $250 \mathrm{mg} / \mathrm{m}^{2}$ weekly; and $400 \mathrm{mg} / \mathrm{m}^{2}$ as a loading dose with maintenance doses at $250 \mathrm{mg} / \mathrm{m}^{2}$ weekly). The loading dose of $400 \mathrm{mg} / \mathrm{m}^{2}$ followed by a maintenance dose of $250 \mathrm{mg} / \mathrm{m}^{2}$ achieved a high percentage of saturation of EGFR in tumor tissue, and these doses were recommended for Phase II or III clinical trials. Combined cetuximab and cisplatin therapy did not appear to induce overlapping toxic effects in this Phase I study. 
Robert et $\mathrm{al}^{26}$ demonstrated that cetuximab at a loading dose of 400 or $500 \mathrm{mg} / \mathrm{m}^{2}$ followed by a weekly maintenance dose of $250 \mathrm{mg} / \mathrm{m}^{2}$ could be safely combined with conventionally fractionated RT (70 Gy in 2 Gy fractions) and hyperfractionated RT (76.8 Gy in 1.2 Gy fractions twice daily) in patients with LA-SCCHN.

\section{Efficacy studies, including any comparative studies}

The results of published or presented randomized Phase III trials with cetuximab in SCCHN are summarized in Table 1.

\section{LA-SCCHN}

\section{Cetuximab in combination with RT}

Bonner et $\mathrm{al}^{27,28}$ conducted a multinational, randomized study to compare RT alone with RT plus cetuximab, in the treatment of stage III or IV nonmetastatic, measurable SCC of the oropharynx, hypopharynx, or larynx. Patients were randomly assigned to treatment with RT alone (213 patients) or RT plus weekly cetuximab (211 patients) at the summary of product characteristics (SPC) recommended dose (initial loading dose of $400 \mathrm{mg} / \mathrm{m}^{2}$ followed by weekly administration of $\left.250 \mathrm{mg} / \mathrm{m}^{2}\right) \cdot{ }^{29,30} \mathrm{RT}$ consisted of one of the following three regimens: once daily RT delivered at 2 Gy per day to a total dose of 70 Gy to gross disease; twice daily RT delivered as $1.2 \mathrm{~Gy}$ in two separate fractions each day (separated by $\geq 6$ hours) to a total dose of 72.0-76.8 Gy; and concomitant boost RT delivered as 1.8 Gy per day for 30 fractions, with a second fraction of 1.5 Gy delivered more than 6 hours after the first fraction during the last 12 days of treatment for a total dose of 72 Gy. At least 50-54 Gy was to be delivered to the uninvolved nodal areas of the neck. Grossly involved neck nodes could receive the reduced gross disease dose of 60 Gy if a neck dissection was planned after RT. The median duration of locoregional control (primary endpoint) was 24.4 months among patients treated with cetuximab plus RT and 14.9 months among those given RT alone (hazard ratio [HR] for locoregional progression or death: $0.68 ; P=0.005)$. RT plus cetuximab significantly prolonged progression-free survival (PFS) (HR for disease progression or death: 0.70; $P=0.006)$. Median OS for patients treated with cetuximab and RT was 49.0 months (95\% confidence interval [CI]: 32.8-69.5) versus 29.3 months (95\% CI: 20.6-41.4) in the RT alone group (HR: 0.73 ; 95\% CI: $0.56-0.95 ; P=0.018$ ). The 5 -year OS rate was $45.6 \%$ in the cetuximab plus RT group and $36.4 \%$ in the RT alone group. For the patients treated with cetuximab, OS was significantly improved in those who experienced an acneiform rash of at least grade 2 severity compared with patients with no rash or grade 1 rash (HR: 0.49 ; 95\% CI: $0.34-0.72 ; P=0.002) .{ }^{27,28}$

The efficacy results of an adequately sized Phase III trial comparing cetuximab plus RT with cisplatin-based CRT have not been reported thus far. Therefore cisplatin-based CRT is still widely accepted as the standard treatment for patients with LA-SCCHN, based on the solid results of a large meta-analysis including data on 17,346 patients which showed an absolute survival benefit at 5 years of $6.5 \%$ with the concomitant administration of chemotherapy and RT. ${ }^{31}$ In contrast, the benefit of cetuximab has only been demonstrated in one single randomized trial involving 424 patients. ${ }^{27,28}$

Data from retrospective analyses at least do not support the substitution of cisplatin by cetuximab in association

Table I Randomized Phase III trials with cetuximab in SCCHN

\begin{tabular}{|c|c|c|c|c|c|c|}
\hline Author & Treatment & $\mathbf{N}$ & LRC (months) & OS (months) & PFS (months) & ORR \\
\hline \multicolumn{7}{|c|}{ Locoregionally advanced disease } \\
\hline \multirow[t]{3}{*}{ Bonner et $\mathrm{a}^{27,28}$} & RT & 213 & $14.9 *$ & 29.3 & & $64 \%$ \\
\hline & $\mathrm{RT}+$ cetuximab & 211 & $24.4^{*}$ & 49 & & $74 \%$ \\
\hline & $P$-value & & 0.005 & 0.018 & 0.006 & 0.02 \\
\hline \multirow[t]{3}{*}{ Ang et $\mathrm{al}^{45}$} & CRT & 448 & & $79.7^{\ddagger}$ & $64.3^{*, t}$ & \\
\hline & CRT + cetuximab & 447 & & $82.6^{\ddagger}$ & $63.4^{*, \dagger}$ & \\
\hline & $P$-value & & & 0.17 & 0.67 & \\
\hline \multicolumn{7}{|c|}{ Recurrent/metastatic disease } \\
\hline \multirow[t]{3}{*}{ Vermorken et al ${ }^{68}$} & Platinum/5-FU & 220 & & $7.4^{*}$ & 3.3 & $20 \%$ \\
\hline & Platinum/5-FU + cetuximab & 222 & & $10.7^{*}$ & 5.6 & $36 \%$ \\
\hline & $P$-value & & & 0.04 & $<0.001$ & $<0.001$ \\
\hline \multirow[t]{3}{*}{ Burtness et $\mathrm{al}^{67}$} & Cisplatin + placebo & 60 & & 8 & $2.7^{*}$ & $10 \%$ \\
\hline & Cisplatin + cetuximab & 57 & & 9.2 & $4.2 *$ & $26 \%$ \\
\hline & $P$-value & & & 0.21 & 0.09 & 0.03 \\
\hline
\end{tabular}

Notes: *Primary endpoint; ${ }^{\dagger} 2$-year PFS rate; ${ }^{\ddagger} 2$-year OS rate. Platinum $/ 5$-FU: cisplatin $\left(100 \mathrm{mg} / \mathrm{m}^{2}\right)$ or carboplatin (AUC 5$)$ on day I, followed by 5 -FU I000 $\mathrm{mg} / \mathrm{m}^{2} /$ day as a continuous infusion day I-4.

Abbreviations: RT, radiotherapy; CRT, chemoradiation; N, number of patients; LRC, locoregional control; OS, overall survival; PFS, progression-free survival; ORR, overall response rate. 
with RT in LA-SCCHN patients who can tolerate CRT. Koutcher et $\mathrm{al}^{32}$ retrospectively compared 174 consecutive, newly diagnosed LA-SCCHN patients treated from March 1, 2006 to April 1, 2008 with RT and either singleagent cisplatin $(n=125)$ or cetuximab $(n=49)$. Patients who received additional concurrent, induction, or adjuvant systemic therapy, weekly cisplatin, prior head and neck RT, or primary surgical resection were excluded. At a median follow-up of 22.5 months for living patients, the 2-year locoregional failure rate was $5.7 \%$ for RT with cisplatin and $39.9 \%$ for RT with cetuximab $(P<0.0001)$. The 2 -year failure-free survival and OS rates were $87.4 \%$ versus $44.5 \%$ $(P<0.0001)$ and $92.8 \%$ versus $66.6 \%(P=0.0003)$, respectively, in favor of cisplatin. The results were upheld on multivariate analysis. Late grade 3 or 4 toxicity and feeding tube dependency 9 months after completion of RT were similar in the two groups. Obviously, the results have to be interpreted cautiously because of the retrospective nature of the study and significant differences in patient characteristics; ie, the patients treated with cetuximab being older and having a lower creatinine clearance.

Walsh et $\mathrm{al}^{33}$ retrospectively reviewed acute toxicity in 34 patients treated with cetuximab and RT at St Luke's Hospital in Dublin, Ireland, comparing it with a matched group of 33 patients treated with cisplatin and RT at the same institution. The cetuximab group experienced significantly more $\geq$ grade 3 oral mucositis $(P=0.014)$ and skin dermatitis $(P=0.0004)$, more $\geq 10 \%$ weight loss $(P=0.03)$, and required more enteral feeding $(P=0.05)$.

Chew et $\mathrm{al}^{34}$ retrospectively analyzed 190 files of patients treated at the British Columbia Cancer Agency with RT and either cisplatin $100 \mathrm{mg} / \mathrm{m}^{2}$ on day 1,22 , and 43, or weekly cetuximab. Cetuximab treated patients were significantly older (median 63.1 versus 56.5 years). Cisplatin treated patients required more dose reductions and dose delays. Weight loss was higher in cisplatin treated patients. There was a trend to more unexpected admissions and feeding tube insertions with cisplatin. However, there was a difference in locoregional relapse rate in favor of cisplatin $(7.6 \%$ versus $20.8 \% ; P=0.008)$.

Shapiro et $\mathrm{al}^{35}$ retrospectively reviewed the records of patients treated at Memorial Sloan Kettering Cancer Center with either concurrent cetuximab, concurrent 5-fluorouracil (FU)/carboplatin, or concurrent high dose cisplatin, and intensity-modulated RT (IMRT). Patients receiving cetuximab or 5-fluorouracil (5-FU)/carboplatin were significantly older, had a lower performance status, a higher Charlson score, a higher $\mathrm{T}$ stage, and a worse renal function. After adjusting for risk factors, there was no significant difference in locoregional relapse-free survival or OS between patients treated with cisplatin or with 5-FU/carboplatin. Late toxicity was worst with the latter regimen. However, cetuximab and RT treatment resulted in a significantly inferior OS and locoregional relapse-free survival.

Pryor et $\mathrm{al}^{36}$ reviewed acute toxicity data from 42 patients receiving cetuximab and $\mathrm{RT}$ and a matched cohort of 36 patients receiving CRT or altered fractionation RT. Cetuximab treated patients experienced higher rates of grade 3 or greater cheilitis $(26 \%$ versus $6 \%, P=0.01)$ and anterior stomatitis (38\% versus $6 \%, P=0.002)$. Overall, these retrospective data do not seem to be in favor of replacing cisplatin and RT by cetuximab and RT when patients are able to tolerate cisplatin and RT.

\section{Cetuximab in combination with CRT}

The addition of cetuximab to cisplatin-based CRT in patients with LA-SCCHN was demonstrated to be feasible. ${ }^{37-41}$ Efficacy data in Phase II trials were promising. Concurrent delivery of weekly carboplatin at an area under the curve of $2 \mathrm{mg}$ per $\mathrm{mL}$ per minute, (AUC 2), paclitaxel $40 \mathrm{mg} / \mathrm{m}^{2}$, cetuximab, and RT (1.8 Gy per day up to $70.2 \mathrm{~Gy}$ ) was well-tolerated and resulted in encouraging local control and survival rates in a Phase II study enrolling 43 patients. ${ }^{40}$

Merlano et $\mathrm{al}^{42}$ treated 45 patients with stage III-IV nonmetastatic (M0) SCCHN with RT administered as a single daily fraction (days $1-5$ in weeks $2-3,5-6$, and 8-10 up to a dose of $50 \mathrm{~Gy} / 2$ Gy per fraction) to the clinical target volume, including the tumor, the metastatic lymph nodes, and the draining clinical negative lymphatic pathways. A further boost up to 66-70 Gy was prescribed to the tumor and the metastatic lymph nodes. Chemotherapy consisted of cisplatin $20 \mathrm{mg} / \mathrm{m}^{2} /$ day and 5-FU $200 \mathrm{mg} / \mathrm{m}^{2} /$ day on days 1-5 of weeks 1,4 , and 7. Cetuximab was delivered weekly on day 1 , from weeks 1 to 10 . Acute grade 3-4 toxic effects were in the expected range, although grade 3 radiodermatitis occurred in $73 \%$ of the patients. The complete response rate (primary endpoint) was $71 \%$.

Kao et $\mathrm{al}^{37}$ treated 33 patients with stage IVa or IVb SCCHN with simultaneous integrated boost IMRT, 5-FU and hydroxyurea, and cetuximab. RT was administered at $1.5 \mathrm{~Gy}$ per fraction twice daily, on days 1 through 5 on an alternating week schedule. Macroscopic tumor volume received from 72-73.5 Gy, microscopic positive margins received 66 Gy, high risk microscopic disease received 54-63 Gy, and low risk microscopic disease received 43.2-48 Gy. Systemic treatment consisted of continuous-infusion 5-FU at a dose of $600 \mathrm{mg} / \mathrm{m}^{2}$ daily for 120 hours, hydroxyurea $500 \mathrm{mg}$ orally every 12 hours 
on days 1 through 5, and cetuximab administered on day 1 . No anticancer therapy was administered on days 6 through 14. After a median follow-up of 24 months, the 2-year rates of locoregional control, distant control, disease-free survival, and OS were $83 \%, 79 \%, 69 \%$, and $86 \%$, respectively. Grade 3 toxicity consisted of mucositis in 33\% of patients, radiation dermatitis in $15 \%$ of patients, anemia in $18 \%$ of patients, leucopenia in $18 \%$ of patients, neutropenia in $12 \%$ of patients, and thrombocytopenia in $3 \%$ of patients.

Tong et $\mathrm{a}^{41}$ also conducted a Phase II trial evaluating the tolerability and efficacy of incorporating cetuximab and simultaneous integrated boost IMRT into the 5-FU and hydroxyurea CRT regimen in 65 patients with stage IVa or $\mathrm{IVb}$ or high risk stage III SCCHN. At a median follow-up of 28 months, 2-year locoregional control, distant control, PFS, event-free survival, and OS were $79 \%, 83 \%, 72 \%$, $63 \%$, and $80 \%$, respectively. p16 expression was associated with a significantly better outcome. The most common grade 3-4 toxicities were mucositis (46\%), leukopenia (18\%), anemia (18\%), and dermatitis (17\%).

Seiwert et $\mathrm{al}^{39}$ randomized 110 patients with LA-SCCHN, who had received two cycles of carboplatin, paclitaxel, and cetuximab as induction chemotherapy (ICT), between weekly cetuximab in combination with either 5-FU, hydroxyurea, and hyperfractionated week-on week-off RT (72-74 Gy) (CetuxFHX), or cisplatin accelerated RT with concomitant boost (72 Gy) (CetuxPX). After a median follow-up of 21 months, 2-year OS rates were $89.5 \%$ with CetuxFHX and 91.4\% with CetuxPX. Two-year PFS rates were $82.3 \%$ and $89.7 \%$, respectively $(P=0.18)$. Grade 3 or greater mucositis was present in 91.1\% (CetuxFHX) and 94.3\% (CetuxPX) of patients; grade 3 or greater dermatitis was present in $82.1 \%$ (CetuxFHX) and 50.9\% (CetuxPX) of patients. Ninety-five percent of the patients completed therapy, demonstrating that cetuximab can be incorporated safely in both CRT platforms.

Conflicting data have been presented on the feasibility of the combination of RT, cetuximab, and pemetrexed. ${ }^{43,44}$

Unfortunately, the addition of cetuximab to cisplatinbased CRT does not seem to further improve the outcome. In Radiation Therapy Oncology Group (RTOG) 0522, ${ }^{45}$ 895 evaluable patients with stage III or IV nonmetastatic SCCHN were randomized to receive either CRT (72 Gy in 42 fractions over 6 weeks plus cisplatin $100 \mathrm{mg} / \mathrm{m}^{2}$ on days 1 and 22) or the same regimen plus weekly cetuximab. At the time of the third interim analysis, after 337 events and after a median follow-up of 2.4 years for the surviving patients, the conditional power of the trial becoming positive was below $10 \%$, triggering early reporting. Over $90 \%$ of the patients received the planned two doses of cisplatin in both arms. The 2-year PFS (primary endpoint) was $64.3 \%$ with CRT and 63.4\% with CRT plus cetuximab (HR: 1.05; 95\% CI: $0.84-1.29 ; P=0.67)$. The 2 -year OS rates were $79.7 \%$ and $82.6 \%$, respectively (HR: 0.87; 95\% CI: 0.66-1.15; $P=0.17)$. The estimated 2-year locoregional relapse rate was $19.8 \%$ and $24.5 \%$, respectively $(P=0.92)$. The 2 -year distant metastasis rate was $12.0 \%$ and $7.6 \%$, respectively $(P=0.07)$. Overall, there was no difference regarding acute grade 3 or 4 toxicities between both arms. However, grade 3 or 4 mucositis (33\% in CRT versus $43 \%$ in CRT plus cetuximab) and in-field dermatitis (15\% in CRT versus $25 \%$ in CRT plus cetuximab) was more common in the cetuximab containing arm. Grade 3 or 4 dermatitis outside the radiation field occurred in $19 \%$ of the patients treated with cetuximab.

\section{Cetuximab administered adjuvantly}

Mesia et $\mathrm{a}^{46}$ randomly assigned 91 stage III-IV M0 oropharyngeal tumors to treatment with accelerated concomitant boost RT (69.9 Gy) with cetuximab or the same treatment with the addition of 12 consecutive weeks of cetuximab maintenance therapy. The locoregional control rate at 1 year (primary endpoint) was higher among patients in the experimental arm, treated with cetuximab maintenance $(59 \%$ versus $47 \%$ ), although the difference was not statistically significant $(P=0.25)$. Moreover, the increase in locoregional control was not maintained after 2 years of follow-up (44\% in both arms), suggesting that an EGFR blockade of limited duration is not sufficient to eliminate minimal residual disease.

\section{Cetuximab and ICT}

The role of ICT in the treatment of LA-SCCHN remains controversial. ${ }^{47-50}$ The association of cetuximab and ICT was tested in several Phase II studies and found to be feasible in most. ${ }^{51-54}$ Efficacy data were promising and support further evaluation.

Argiris et $a^{51}$ added weekly cetuximab to docetaxel $75 \mathrm{mg} / \mathrm{m}^{2}$ on day 1 , cisplatin $75 \mathrm{mg} / \mathrm{m}^{2}$ on day 1 (TPE), repeated every 21 days for three cycles, followed by RT with concurrent cisplatin $30 \mathrm{mg} / \mathrm{m}^{2}$ and cetuximab weekly (XPE), and maintenance cetuximab for 6 months. Of 39 enrolled patients, 36 had stage IV disease and 23 an oropharyngeal primary. Acute toxicities during TPE included neutropenic fever (10\%); during XPE, acute toxicities included grade 3 or 4 oral mucositis (54\%) and hypomagnesemia (39\%). With a median follow-up of 36 months, 3-year PFS and OS rates were $70 \%$ and $74 \%$, respectively. 
Kies et $\mathrm{al}^{52}$ added cetuximab to ICT consisting of six weekly cycles of paclitaxel $135 \mathrm{mg} / \mathrm{m}^{2}$ and carboplatin (AUC 2). The most common grade 3 or 4 toxicity was skin rash (45\%), followed by neutropenia (21\%) without fever. After ICT, $19 \%$ of the patients achieved a complete response and $77 \%$ achieved a partial response. After ICT, patients underwent risk-based local therapy, which consisted of either RT, CRT, or surgery, based on tumor stage and site at diagnosis. In Eastern Cooperative Oncology Group (ECOG) E2303, ${ }^{53} 63$ patients with resectable stage III or IV SCCHN were treated with 6-week cycles of paclitaxel, carboplatin (AUC 2), and cetuximab, followed by CRT (weekly paclitaxel $30 \mathrm{mg} / \mathrm{m}^{2}$, carboplatin AUC 1, and cetuximab). If at week 14, after a radiation dose of $50 \mathrm{~Gy}$, tumor was still present on biopsy, salvage surgery was performed. In case of a negative biopsy ( $9 \%$ of the patients), CRT was continued to a total dose of 68-72 Gy. Two-year PFS and OS rates were $82 \%$ and $66 \%$, respectively. A local recurrence occurred in $17.5 \%$ of the patients.

Adkins et $\mathrm{al}^{54}$ treated 30 patients with stage III or IV SCCHN with ICT consisting of nab-paclitaxel $100 \mathrm{mg} / \mathrm{m}^{2}$ weekly on days 1,8 , and 15 ; weekly cetuximab at the SPC recommended dose; cisplatin $75 \mathrm{mg} / \mathrm{m}^{2}$ on day 1 ; and 5 -FU $750 \mathrm{mg} / \mathrm{m}^{2} /$ day as a continuous infusion on days $1-3$ (ACPF). Patients received three 3 -week cycles prior to CRT consisting of IMRT 70 Gy in 35 fractions of 2 Gy over 7 weeks and cisplatin $100 \mathrm{mg} / \mathrm{m}^{2}$ on days 1,22 , and 43 . One patient died during ICT due to a neutropenia-related pneumonia. Three patients could not be treated with cisplatin according to protocol due to toxicity. The complete response rate at the primary tumor site after two cycles of ACPF was 53\% and the overall response rate was $100 \%$. Twenty-nine (96\%) patients completed three cycles of ACPF, 26 (90\%) completed definitive RT per protocol, and 22 of the 27 evaluable patients (81\%) received at least two of the three planned doses of cisplatin with RT. The estimated 2-year OS and PFS rates were $84 \%$ and $65 \%$, respectively.

The addition of cetuximab to full dose docetaxel/ cisplatin/5-FU (TPF) appears to be toxic. The European Organisation for the Research and Treatment of Cancer $(\text { EORTC })^{55}$ treated 47 patients with unresectable stage III or IV M0 SCCHN with four 3-week cycles of European TPF (docetaxel $75 \mathrm{mg} / \mathrm{m}^{2}$ and cisplatin $75 \mathrm{mg} / \mathrm{m}^{2}$ on day 1 , followed by 5 -FU $750 \mathrm{mg} / \mathrm{m}^{2} /$ day on days $1-5$ ) with prophylactic antibiotics. Cetuximab at the recommended dose was started on day 1 of the first cycle and was to be given weekly until the end of RT. If at least stable disease was observed after four cycles of TPF, patients were randomized to CRT either with weekly cisplatin $40 \mathrm{mg} / \mathrm{m}^{2}$ or with weekly carboplatin
(AUC 1.5). Patients with progressive disease on ICT went off the study. The primary endpoint was the feasibility to reach at least $80 \%$ of per protocol dose intensity of RT, cisplatin, and cetuximab. The trial was stopped early because of safety concerns. Grade 3-5 events included cardiac events (one patient, grade 3), febrile neutropenia (four patients, one grade 4), infection (four patients, one grade 4), mucositis/stomatitis (four patients, one grade 4), bowel perforation (three patients, grade 4), upper gastrointestinal bleeding (one grade 4), and pulmonary events (four patients $\geq$ grade 4 ). There were two deaths (one due to unknown cause at day 19 and one due to septic shock at 31 days after the start of treatment). ${ }^{55}$

In a Phase I study ${ }^{56}$ using the American TPF regimen, which consists of three 3-week cycles of docetaxel $75 \mathrm{mg} / \mathrm{m}^{2}$ on day 1 , cisplatin $100 \mathrm{mg} / \mathrm{m}^{2}$ on day 1 , and $5-\mathrm{FU}$ $1000 \mathrm{mg} / \mathrm{m}^{2} /$ day administered as a continuous infusion on days $1-4$, the $5-\mathrm{FU}$ dose had to be reduced to $850 \mathrm{mg}$ / $\mathrm{m}^{2} /$ day. The main toxicity was gastrointestinal (mucositis, diarrhea, and enteritis).

Jordan et al ${ }^{57}$ treated $152 \mathrm{SCCHN}$ patients with $\mathrm{T} 3$ or $\mathrm{T} 4$ tumors with three 3-week cycles of TPF (docetaxel $75 \mathrm{mg} / \mathrm{m}^{2}$ on day 1 , cisplatin $35 \mathrm{mg} / \mathrm{m}^{2}$ on days 1 and 2, and $5-\mathrm{FU}$ $750 \mathrm{mg} / \mathrm{m}^{2} /$ day, as a continuous infusion on days $1-5$, with pegfilgrastim support) followed by CRT (63 Gy in 35 fractions of 1.8 Gy over 7 weeks and weekly cisplatin, $40 \mathrm{mg} / \mathrm{m}^{2}$ ) plus weekly cetuximab. The complete response rate in the 142 patients who were evaluated after the completion of therapy was $57 \%$. Grade 3 or 4 toxicities occurred in 34 of the 142 patients (24\%). In 15 patients, CRT had to be interrupted due to dermatitis.

An attractive approach might be the sequential administration of ICT prior to RT with cetuximab. Ghi et $\mathrm{al}^{58}$ randomized 420 patients to RT either with two cycles of cisplatin/5-FU during weeks 1 and 6 of radiotherapy, or with weekly cetuximab, or to the same treatment (RT either with two cycles of cisplatin/5-FU, or with weekly cetuximab) preceded by 3-weekly cycles of TPF (docetaxel $75 \mathrm{mg} / \mathrm{m}^{2}$ and cisplatin $80 \mathrm{mg} / \mathrm{m}^{2}$ on day 1 , followed by $5-\mathrm{FU} 800 \mathrm{mg} / \mathrm{m}^{2} /$ day as continuous infusion for 96 hours), according to a $2 \times 2$ factorial design. No advantage for cetuximab with RT over CRT was observed regarding grade 3-4 in-field toxicities and feasibility. Treatment compliance was superior with CRT.

In the TREMPLIN Phase II trial, ${ }^{59} 110$ patients with SCC of the larynx or hypopharynx suitable for total laryngectomy were treated with three 3-week cycles of TPF (docetaxel $75 \mathrm{mg} / \mathrm{m}^{2}$ and cisplatin $75 \mathrm{mg} / \mathrm{m}^{2}$ on day 1 , followed by $5-\mathrm{FU}$ $750 \mathrm{mg} / \mathrm{m}^{2} /$ day on days $\left.1-5\right)$. Patients who obtained at least a partial response ( $82 \%$ of the patients) were randomized to receive RT ( 70 Gy in 35 fractions over 7 weeks) either with 
cisplatin $100 \mathrm{mg} / \mathrm{m}^{2}$ on days 1,22 , and 43 , or with weekly cetuximab. Treatment compliance was better in the cetuximab arm with $71 \%$ of the patients receiving all planned cetuximab administrations versus $42 \%$ of the patients receiving the planned three cycles of cisplatin. There was no difference in grade 3 or 4 mucosal toxicity, but grade 3 or 4 in-field dermatitis was more frequently observed with cetuximab (57\% versus $26 \% ; P<0.001)$. Grade 1 renal dysfunction at last evaluation was observed in $22.4 \%$ of the patients treated with cisplatin. The larynx preservation rate 3 months after treatment (primary endpoint) was 95\% with cisplatin versus $93 \%$ with cetuximab. The locoregional failure rate after a median follow-up of 36 months was $11.7 \%$ with cisplatin and $21.4 \%$ with cetuximab. However, more salvage laryngectomies were performed in the cetuximab arm, resulting in a similar ultimate locoregional failure rate in the two arms (10\% with cisplatin versus $8.9 \%$ with cetuximab). The 2-year laryngoesophageal dysfunction-free survival was $79 \%$ with cisplatin versus $71 \%$ with cetuximab $(P=0.3) .{ }^{59}$

Keil et $\mathrm{al}^{60}$ treated $49 \mathrm{LA}-\mathrm{SCCHN}$ patients with three 3-weekly cycles of TPF (docetaxel $75 \mathrm{mg} / \mathrm{m}^{2}$ day and cisplatin $75 \mathrm{mg} / \mathrm{m}^{2}$ day 1 , and infusional $5-\mathrm{FU} 750 \mathrm{mg} / \mathrm{m}^{2} /$ day on days 1-5) followed by RT plus cetuximab at the recommended dose. After completion of ICT, 44 of 49 patients received RT plus cetuximab. Three months after therapy completion, tumor response was observed in 33 patients and after 2 years, 25 patients still had a complete response. The most common grade 4 toxicity during the whole treatment period was dermatitis $(30 \%)$, followed by mucositis $(27 \%)$, and neutropenia (17\%) without fever. One toxic related death was observed during ICT. The 2-year PFS rate was 59\% and the 2 -year OS rate was $63 \%$.

\section{Reirradiation}

Promising efficacy data with acceptable toxicity were reported with reirradiation and cetuximab in a small series of studies of patients with locoregional recurrent and inoperable SCCHN. ${ }^{61-64}$ Balermpas et al ${ }^{62}$ treated 18 patients with an inoperable recurrence of SCCHN after prior adjuvant or definitive RT and simultaneous or sequential cisplatin-based chemotherapy for primary SCCHN, with cetuximab and RT (1.8 Gy/fraction/day over 5-6 weeks resulting in a median total dose of $50.4 \mathrm{~Gy}$ ). Overall response rate was $47 \%$. The median OS and PFS were 8.4 months and 7.3 months, respectively. The OS rate was $44 \%$ at 1 year, with a 1 -year local control rate of $33 \%$.

Comet et $\mathrm{al}^{63}$ treated 40 patients with an inoperable recurrent, or new primary tumor, in a previously irradiated area with $36 \mathrm{~Gy}$ in six fractions to the $85 \%$ isodose line covering $95 \%$ of the planning target volume. Fifteen patients received concomitant cetuximab without major additional toxicity.

Akmansu et $\mathrm{al}^{61}$ reirradiated nine patients with doses ranging between 20-70 Gy with concomitant cetuximab. During RT, four patients had grade 2 and five patients had grade 3 skin toxicity.

A single institution matched case-control study comparing two groups of 35 patients each, treated with stereotactic body reradiation therapy alone or with weekly cetuximab infusion during RT, suggests an OS benefit with the addition of cetuximab (24.5 months versus 14.8 months), without a significant increase in grade 3 or 4 toxicities. ${ }^{65}$ Concomitant cetuximab with reirradiation seems to be a reasonable approach for unresectable recurrent SCCHN and should be tested in a prospective randomized trial. ${ }^{65}$

\section{Cetuximab with postoperative CRT}

In a Phase II trial conducted by RTOG, ${ }^{66}$ patients with high-risk pathologic features, were randomized to receive a combination of RT (60 Gy) and cetuximab plus either weekly cisplatin $30 \mathrm{mg} / \mathrm{m}^{2}$ (arm A) or weekly docetaxel $15 \mathrm{mg} / \mathrm{m}^{2}$ (arm B). Treatment-related toxicity was moderate and comparable between the treatment arms. With a median follow-up of 2.5 years, 2-year OS rates were $69 \%(95 \%$ CI, 60\%-79\%) and 79\% (95\% CI, 71\%-87\%) for arms A and $\mathrm{B}$, respectively; 2-year disease-free survival rates were $57 \%$ (95\% CI, 47\%-67\%) and 66\% (95\% CI, 56\%-75\%), respectively. The study suggests that further studies with taxane-based chemo-bio-radiation with cetuximab are warranted.

\section{$\mathrm{R} / \mathrm{M}-\mathrm{SCCHN}$}

\section{First line R/M-SCCHN}

$\mathrm{ECOG}^{67}$ randomly assigned 117 evaluable R/M-SCCHN patients to receive cisplatin $100 \mathrm{mg} / \mathrm{m}^{2}$ every 4 weeks, with weekly cetuximab ( $\operatorname{arm} \mathrm{A})$ or placebo ( $\operatorname{arm} \mathrm{B})$. Median PFS was 2.7 months for arm B and 4.2 months for arm A. The HR for progression (primary endpoint) of arm A versus arm B was 0.78 (95\% CI: $0.54-1.12 ; P=0.09)$. The $22 \%$ reduction in risk of progression was not significant in a study powered to detect a $50 \%$ reduction in hazard rates. To detect a 2 -month prolongation of median PFS from 2.7 months with $90 \%$ power, approximately 173 patients would have been required, rather than the 123 enrolled in the study. Median OS was 8.0 months for arm B and 9.2 months for $\operatorname{arm~A~}(P=0.21)$. The objective response rate was $26 \%$ for arm $A$ and $10 \%$ for $\operatorname{arm} \mathrm{B}(P=0.03)$. Although the ECOG study failed to meet its primary endpoint, the results nevertheless were in line 
with the outcome in the Erbitux in First-Line Treatment of Recurrent or Metastatic Head and Neck Cancer (EXTREME) trial, which indeed met its primary endpoint. ${ }^{68}$ In that trial, Vermorken et $\mathrm{al}^{68}$ randomized 442 patients with previously untreated R/M-SCCHN to receive cisplatin $\left(100 \mathrm{mg} / \mathrm{m}^{2}\right)$ or carboplatin (AUC 5) on day 1 , followed by 5 -FU $1000 \mathrm{mg} / \mathrm{m}^{2} /$ day as a continuous infusion for 4 days, every 3 weeks for a maximum of six cycles or the same chemotherapy plus cetuximab at the SPC recommended dose. Patients with at least stable disease who received chemotherapy plus cetuximab continued to receive cetuximab until disease progression or unacceptable toxic effects, whichever occurred first. The median OS was 7.4 months in the chemotherapy-alone group and 10.1 months in the group that received chemotherapy plus cetuximab (HR for death, 0.80 ; 95\% CI: $0.64-0.99 ; P=0.04$ ). The addition of cetuximab prolonged the median PFS from 3.3 months to 5.6 months (HR for progression, $0.54 ; 95 \%$ CI: 0.43 to $0.67 ; P<0.001)$. The response rate was $20 \%$ (95\% CI: 15-25) and 36\% (95\% CI: 29-42) $(P<0.001)$, respectively. Neither the amount of EGFR expression nor the tumor EGFR copy number were a predictive marker for any benefit from the addition of cetuximab. ${ }^{69}$

Taxanes are among the most active cytotoxic agents in SCCHN. ${ }^{70}$ Promising results were observed in non-randomized Phase II trials when cetuximab was added to a taxane, either as a single agent or in combination with cisplatin. ${ }^{71-74}$ Hitt et $\mathrm{al}^{71}$ enrolled 46 patients who were unlikely to benefit from platinum-based chemotherapy in a Phase II trial combining weekly paclitaxel $80 \mathrm{mg} / \mathrm{m}^{2}$ and cetuximab at the recommended dose. The overall response rate was 54\% (95\% CI: 39\%-69\%) (complete response rate: $22 \%$, disease control rate: $80 \%)$. Median PFS and OS were 4.2 months (95\% CI: 2.9-5.5 months) and 8.1 months (95\% CI: 6.6-9.6 months), respectively. Common grade 3 or 4 adverse events were acnelike rash (24\%), asthenia (17\%), and neutropenia (13\%). The development of acne-like rash was associated with tumor response. Patients who had not previously received chemotherapy as part of a multimodal treatment of locally advanced disease had a significantly better tumor response $(P=0.020)$ than those who had received prior chemotherapy.

In the GORTEC 2008-3 trial, ${ }^{72} 54$ patients with previously untreated R/M-SCCHN were treated with weekly cetuximab and four 3-week cycles of docetaxel $75 \mathrm{mg} / \mathrm{m}^{2}$ and cisplatin $75 \mathrm{mg} / \mathrm{m}^{2}$, followed by maintenance cetuximab until disease progression or unacceptable toxicity. Toxicity was manageable with granulocyte colony-stimulating factor support. The overall response rate (primary endpoint) was 54\%. Median PFS and OS were 7.1 months and 15.3 months, respectively.
These data compare favorably with the results observed with cisplatin, 5-FU, and cetuximab in the EXTREME trial.

Clark et $\mathrm{al}^{73}$ conducted a Phase I pilot study combining oxaliplatin, 5-FU, and cetuximab in patients with untreated R/M-SCCHN. Oxaliplatin $100 \mathrm{mg} / \mathrm{m}^{2}$ on day 1, 5-FU $750 \mathrm{mg} /$ $\mathrm{m}^{2}$ /day over 96 hours beginning on day 1, and weekly cetuximab every 21 days was determined as the maximum tolerated dose. However, observed responses were short-lived.

Vermorken et $\mathrm{al}^{74}$ treated $60 \mathrm{R} / \mathrm{M}-\mathrm{SCCHN}$ patients who had received no more than one prior systemic therapy for LA-SCCHN with pemetrexed $500 \mathrm{mg} / \mathrm{m}^{2}$ with vitamin supplementation and cisplatin $75 \mathrm{mg} / \mathrm{m}^{2}$ on day 1 , administered every 3 weeks, and weekly cetuximab. Median PFS was 4.4 months (95\% CI: 3.6-5.4 months) and median OS was 9.7 months (95\% CI: 6.5-13.1 months). The overall response rate was $29.3 \%$ (95\% CI: $18.1 \%-42.7 \%)$. Drug-related grade 3 or 4 toxicities included neutropenia (33.4\%), fatigue $(24.2 \%)$, anorexia (12.1\%), and infection (10.6\%). There were five drug-related deaths $(7.6 \%)$ on treatment. The authors concluded that this regimen could not be seen as a favorable alternative for the presently standard EXTREME PFE (cisplatin $100 \mathrm{mg} / \mathrm{m}^{2}$ on day 1 , followed by 5-FU $1000 \mathrm{mg}$ / $\mathrm{m}^{2} /$ day day $1-4$, every 3 weeks plus cetuximab) regimen.

\section{Pretreated R/M-SCCHN}

The role of cetuximab in platinum-refractory or platinumresistant disease was evaluated in Phase II trials which showed similar overall response rates $(10 \%-13 \%)$, irrespective of whether cetuximab was administered as a single agent or in association with a platinum compound..$^{75-78}$ The median OS of around 6 months compares favorably to the median OS observed in platinum-refractory historical controls. ${ }^{79}$ Therefore, single agent cetuximab seems to be a valuable option for patients with R/M-SCCHN who progressed on platinum-based chemotherapy.

Fury et $\mathrm{l}^{80}$ conducted a multicenter randomized prospective Phase II study in patients who had received no more than two prior cytotoxic chemotherapy regimens for R/MSCCHN. Patients were treated with cetuximab every 2 weeks either at $500 \mathrm{mg} / \mathrm{m}^{2}$ (Group A) or $750 \mathrm{mg} / \mathrm{m}^{2}$ (Group B). The primary end point was response rate. Confirmed partial response rates were $11 \%$ for Group A and 8\% for Group B. Median PFS and median OS were similar for both groups (PFS: 2.2 months and 2.0 months; OS: 7.0 months and 9.4 months for Groups A and B, respectively). The most common cetuximab-related adverse events (all grades) included rash, fatigue, and hypomagnesemia. Cetuximab $500 \mathrm{mg} / \mathrm{m}^{2}$ administered every 2 weeks, although not directly compared 
with a $250 \mathrm{mg} / \mathrm{m}^{2}$ weekly dose, seems to have similar efficacy as conventional dosing for patients with R/M-SCCHN and might be a convenient alternative. Escalating the dose to $750 \mathrm{mg} / \mathrm{m}^{2}$ every 2 weeks clearly does not seem to offer a therapeutic advantage.

Massa et $\mathrm{al}^{81}$ combined vinorelbine on day 1,8 , and 15 every 28 days, and weekly cetuximab in 24 patients with R/M-SCCHN progressing after at least two chemotherapy regimens. Overall response rate and disease control rate was $17 \%$ and $69.5 \%$, respectively. Median PFS was 5.2 months. The regimen was well tolerated.

Knoedler et $\mathrm{al}^{82}$ treated 84 platinum-pretreated R/MSCCHN patients with weekly cetuximab and docetaxel $35 \mathrm{mg} / \mathrm{m}^{2}$ (3 weeks out of 4). The observed partial response rate and disease control rate were $12 \%$ and $39 \%$, respectively. The response rate was independent of previous platinum sensitivity. High expression of EGFR variant III and the EGFR ligand amphiregulin was associated with a worse outcome. ${ }^{83}$

\section{Cetuximab in combination with other targeted agents}

Combinations of targeted agents should be explored with caution as illustrated by the outcome of a Phase I trial conducted by Argiris et al. ${ }^{84}$ In that study of seven SCCHN patients, the addition of bortezomib to cetuximab and radiation therapy led to unexpected early disease progression. Bortezomib antagonized cetuximab- and radiation-induced cytotoxicity, degradation of EGFR, and enhanced pro-survival signal pathway activation in SCCHN tumor biopsies. Argiris et $\mathrm{al}^{85}$ enrolled 46 patients with R/M-SCCHN in a Phase II trial combining weekly cetuximab at the recommended dose and bevacizumab $15 \mathrm{mg} / \mathrm{kg}$ administered on day 1 every 3 weeks. A potent reduction in tumor vascularization was observed. The objective response rate was $16 \%$ and the disease control rate $73 \%$. The median PFS and OS were 2.8 months and 7.5 months, respectively. Grade 3-4 adverse events were as expected and occurred in less than $10 \%$ of patients. These promising data support further evaluation of the combination.

\section{Safety and tolerability}

The most common adverse events with cetuximab administered as a single agent in SCCHN patients are summarized in Table 2. The vast majority of cetuximab-related adverse events are grade 1 or $2 .^{77}$

In the pivotal randomized Phase III trial conducted by Bonner et al, ${ }^{27}$ cetuximab did not exacerbate the common adverse events of RT in SCCHN, including mucositis,
Table 2 Adverse events with second line single agent cetuximab in squamous cell carcinoma of the head and neck

\begin{tabular}{lll}
\hline & All grades & Grade 3-4 \\
\hline Dermatological & & \\
$\quad$ Rash & $49 \%$ & $1 \%$ \\
Acne & $26 \%$ & $0 \%$ \\
Dry skin & $14 \%$ & $0 \%$ \\
$\quad$ Nail disorder & $16 \%$ & $0 \%$ \\
Other & & \\
Fever & $14 \%$ & $1 \%$ \\
Nausea & $13 \%$ & $1 \%$ \\
Vomiting & $11 \%$ & $2 \%$ \\
Dyspnea & $5 \%$ & $4 \%$ \\
Infusion-related reactions & $6 \%$ & $1 \%$ \\
\hline
\end{tabular}

xerostomia, dysphagia, pain, weight loss, and performancestatus deterioration. With the exception of acneiform rash and infusion-related events, the incidence rates of grade 3 to 5 adverse events were similar in the two treatment groups. Adverse events occurring more commonly with the combination of cetuximab and RT than with RT alone in that randomized trial are summarized in Table $3 .^{27}$

However, after the introduction of concurrent RT and cetuximab in routine clinical practice, higher incidences of severe radiation dermatitis than observed in the Bonner trial ${ }^{27}$ were reported. ${ }^{33,36,86-97}$ Potential explanations include the use of different toxicity grading systems and publication bias, but also differences in radiation dose and techniques. ${ }^{98}$ Detailed consensus guidelines, including general and grade-specific measures, for the management of radiation dermatitis in patients receiving RT plus EGFR inhibitors were published in $2008^{99}$ and updated in 2011. ${ }^{100}$

In the EXTREME trial, ${ }^{68}$ the safety profile of the study treatment was consistent with what could be expected with the agents used. For the most part, there was no significant difference in the overall incidence of grade 3 or 4 adverse events between the groups. However, there were nine cases of sepsis (4\%) in the cetuximab group, as compared with one case $(<1 \%)$ in the chemotherapy-alone group $(P=0.02)$, and there were eleven cases $(5 \%)$ of severe hypomagnesemia in the cetuximab group, as compared with three cases $(1 \%)$ in the chemotherapy-alone group $(P=0.05)$. Grade 3 skin reactions occurred in $9 \%$ and $<1 \%$ of the patients, respectively $(P<0.001)$.

In the ECOG trial, ${ }^{67}$ the addition of cetuximab to cisplatin was associated with a statistically significant increase of grade 3 or 4 adverse events ( $90 \%$ versus $73 \% ; P=0.02)$. Neutropenia (30\% versus $14 \% ; P=0.04$ ), overall grade 3 or 4 hematological toxicity (36\% versus $18 \% ; P=0.04)$, and hypomagnesemia 
Table 3 Adverse events occurring more frequently with the addition of cetuximab to radiotherapy

\begin{tabular}{|c|c|c|c|c|c|c|}
\hline & \multicolumn{3}{|l|}{ All grades } & \multicolumn{3}{|l|}{ Grade 3-5 } \\
\hline & Radiotherapy & $\begin{array}{l}\text { Radiotherapy + } \\
\text { cetuximab }\end{array}$ & $P$-value & Radiotherapy & $\begin{array}{l}\text { Radiotherapy + } \\
\text { cetuximab }\end{array}$ & $P$-value \\
\hline Acneiform rash & $10 \%$ & $87 \%$ & $<0.001$ & $1 \%$ & $17 \%$ & $<0.001$ \\
\hline Weight loss & $72 \%$ & $84 \%$ & 0.005 & & & \\
\hline Nausea & $37 \%$ & $49 \%$ & 0.02 & & & \\
\hline Fever & $13 \%$ & $26 \%$ & 0.001 & & & \\
\hline Headache & $8 \%$ & $19 \%$ & 0.001 & & & \\
\hline Pruritus & $4 \%$ & $16 \%$ & $<0.001$ & & & \\
\hline Infusion reaction & $2 \%$ & $15 \%$ & $<0.001$ & $0 \%$ & $3 \%$ & 0.01 \\
\hline Chills & $5 \%$ & $11 \%$ & 0.03 & & & \\
\hline
\end{tabular}

Note:

(14\% versus $0 \% ; P=0.006)$ were more common in the cetuximab containing arm than with single agent cisplatin.

Data from the French pharmacovigilance database analysis suggest that (severe) infusion reactions were more common in SCCHN than in colorectal cancer patients, ${ }^{101}$ confirming an earlier report from North Carolina. ${ }^{102}$

\section{Patient and society focused perspectives Quality of life (QoL)}

Adding cetuximab to platinum/5-FU does not adversely affect the QoL of patients with R/M-SCCHN. ${ }^{103}$ The EORTC Quality of Life Questionnaire-Core 30 (QLQ-C30) and QLQ-Head and Neck 35 (QLQ-H\&N35) modules were used to assess QoL of the patients included in the EXTREME trial. ${ }^{103}$ For QLQ-C30, mean scores at the end of the third cycle and sixth month for platinum/5-FU plus cetuximab were not significantly worse than those for platinum/5-FU alone. Pattern-mixture analysis demonstrated a significant improvement in the global health status/QoL score in the cetuximab arm $(P=0.0415)$ but no treatment differences in the social functioning scale. For QLQ-H\&N35, the mean score for the cetuximab arm was not significantly worse than that for the chemotherapy arm for all symptom scales at all post-baseline visits. At the third cycle, some symptom scores significantly favored the cetuximab arm (pain, swallowing, speech problems, and social eating). ${ }^{103}$

QoL using the EORTC QLQ-C30 and QLQ-H\&N35 was also assessed at baseline, week 4, and at months 4, 8, and 12 post-baseline in the Phase III trial in patients treated with RT with or without cetuximab. ${ }^{27,104}$ Compliance with completion of QoL questionnaires was high in both arms. QoL worsened during treatment and improved after cessation of treatment, reaching baseline levels at 12 months. There were no significant differences in QoL scores between the treatment arms. This was particularly notable for global health status/
QoL, social functioning, social eating, and social contact. Pretreatment global health status/QoL was identified as a significant prognostic variable in these patients. ${ }^{104}$

\section{Cost effectiveness}

The cost effectiveness of cetuximab in the treatment of SCCHN has been evaluated for several health care systems. Overall, the incremental cost effectiveness ratio (ICER) of the addition of cetuximab to RT falls within the range which is generally considered acceptable in the respective countries that were studied. In contrast, the ICER of the addition of cetuximab to chemotherapy in R/M-SCCHN exceeds the commonly accepted thresholds. An evidence review group (ERG) ${ }^{105}$ evaluated the cost effectiveness of cetuximab plus RT for the treatment of LA-SCCHN considered inappropriate for chemoradiotherapy but appropriate for RT. The evaluation was based upon the evidence submitted by Merck Pharmaceuticals to the National Institute for Health and Clinical Excellence (NICE) as part of the single technology appraisal process. The results suggested that cetuximab plus RT was cost effective compared with RT alone under a broad range of different assumptions on the basis of a cost effectiveness threshold of $£ 20,000$. In the base case, the ICER of cetuximab plus RT compared with RT alone in the treatment of patients with LA-SCCHN was $£ 6390$ per additional quality adjusted life year gained (QALY). ${ }^{105}$

Brown et $\mathrm{al}^{106}$ estimated the cost effectiveness of cetuximab in combination with RT compared to RT alone for the treatment of LA-SCCHN for five countries (Belgium, France, Italy, Switzerland, and the United Kingdom). Country-specific costs of care from official sources were applied in the analysis for each country. In the base-case analysis, the ICER/Qaly by ICER and state $\mathrm{xxx}$ dollars/qaly for patients receiving RT with cetuximab compared to RT alone among all countries was in the range of $€ 7538$ to $€ 10,836$. Sensitivity analysis showed the results to be robust. ${ }^{106}$ In Taiwan, the ICER/Qaly by ICER and 
state xxx dollars/qaly for patients receiving RT in combination with cetuximab compared with RT alone was estimated at US\$36,992. ${ }^{107}$ The Liverpool Reviews and Implementation Group ERG evaluated the cost effectiveness of cetuximab for R/M-SCCHN based upon a review of the manufacturer's submission to the NICE as part of the single technology appraisal process. ${ }^{108}$ The manufacturer reported an ICER/Qaly by ICER and state xxx dollars/qaly of $£ 121,367$ and an incremental cost per life-year gained of $£ 92,226$. The ERG was confident that neither model assumptions nor parameter values were likely to introduce sufficient uncertainty to result in cetuximab plus chemotherapy being cost effective for this group of patients. ${ }^{108}$ According to Hannouf et al, ${ }^{109}$ the addition of cetuximab to standard platinum-based chemotherapy in first line treatment of patients with R/M-SCCHN has an ICER that exceeds 100,000 CAD per QALY gained from the perspective of the Canadian public healthcare system, which again is not considered to be cost effective.

\section{Conclusion and place in therapy}

The addition of cetuximab to RT improves locoregional control and OS when compared to RT alone in patients with LA-SCCHN. However, the addition of cetuximab to CRT, although feasible, does not lead to a further improvement.

Moreover, efficacy results of an adequately sized Phase III trial comparing cetuximab plus RT with cisplatinbased CRT have not been reported thus far. Therefore, CRT remains the standard of care for patients with LA-SCCHN for whom surgery is not considered the optimal treatment, provided they can tolerate CRT.

The addition of cetuximab to platinum-based chemotherapy prolongs survival in patients with R/M-SCCHN. The combination of a platinum-based regimen and cetuximab should be considered as the standard first line regimen for patients who can tolerate this treatment.

Single agent cetuximab is a valuable option for patients with R/M-SCCHN who progressed on platinum-based chemotherapy.

\section{Disclosure}

Pol Specenier has no conflict of interest in this work. Jan B Vermorken participated in advisory boards of Merck-Serono, Amgen, Genentech, and Boehringer-Ingelheim.

\section{References}

1. Forastiere A, Koch W, Trotti A, Sidransky D. Head and neck cancer. N Engl J Med. 2001;345(26):1890-1900.

2. The Globocan Project [website on the Internet]. Geneva: World Health Organization; 2010. Available from: http://globocan.iarc.fr/. Accessed January 27, 2013.
3. Head and Neck Cancers [website on the Internet]. Bethesda: National Institutes of Health; 2013. Available from: http://www.cancer.gov/ cancertopics/factsheet/sites-types/head-and-neck. Accessed January 27, 2013.

4. Marur S, D’Souza G, Westra WH, Forastiere AA. HPV-associated head and neck cancer: a virus-related cancer epidemic. Lancet Oncol. 2010;11(8):781-789.

5. Näsman A, Attner P, Hammarstedt L, et al. Incidence of human papillomavirus (HPV) positive tonsillar carcinoma in Stockholm, Sweden: an epidemic of viral-induced carcinoma? Int J Cancer. 2009;125(2):362-366.

6. Attner P, Näsman A, Du J, et al. Survival in patients with human papillomavirus positive tonsillar cancer in relation to treatment. Int J Cancer. 2012;131(5):1124-1130.

7. Attner P, Du J, Näsman A, et al. Human papillomavirus and survival in patients with base of tongue cancer. Int J Cancer. 2011;128(12): 2892-2897.

8. Haddad RI, Shin DM. Recent advances in head and neck cancer. N Engl J Med. 2008;359(11):1143-1154.

9. Ang KK. Multidisciplinary management of locally advanced SCCHN: optimizing treatment outcomes. Oncologist. 2008;13(8):899-910.

10. Grégoire V, Lefebvre JL, Licitra L, Felip E; EHNS-ESMO-ESTRO Guidelines Working Group. Squamous cell carcinoma of the head and neck: EHNS-ESMO-ESTRO Clinical Practice Guidelines for diagnosis, treatment and follow-up. Ann Oncol. 2010;21 Suppl 5:v184-v186.

11. Specenier PM, Vermorken JB. Recurrent head and neck cancer: current treatment and future prospects. Expert Rev Anticancer Ther. 2008;8(3):375-391.

12. Grandis JR. Established and emerging concepts in epidermal growth factor receptor biology. Int J Radiat Oncol Biol Phys. 2007; 69(Suppl 2):S22-S24.

13. Grandis JR, Tweardy DJ. Elevated levels of transforming growth factor alpha and epidermal growth factor receptor messenger RNA are early markers of carcinogenesis in head and neck cancer. Cancer Res. 1993;53(15):3579-3584.

14. Dassonville O, Formento JL, Francoual M, et al. Expression of epidermal growth factor receptor and survival in upper aerodigestive tract cancer. J Clin Oncol. 1993;11(10):1873-1878.

15. Ang KK, Andratschke NH, Milas L. Epidermal growth factor receptor and response of head-and-neck carcinoma to therapy. Int J Radiat Oncol Biol Phys. 2004;58(3):959-965.

16. Specenier P, Vermorken JB. Biologic therapy in head and neck cancer: a road with hurdles. ISRN Oncol. 2012;2012:163752.

17. Specenier PM, Vermorken JB. Targeted therapies in head and neck cancer. Target Oncol. 2007;2(2):73-88.

18. Specenier P, Vermorken JB. Cetuximab in the treatment of squamous cell carcinoma of the head and neck. Expert Rev Anticancer Ther. 2011; 11(4):511-524.

19. Huang SM, Bock JM, Harari PM. Epidermal growth factor receptor blockade with $\mathrm{C} 225$ modulates proliferation, apoptosis, and radiosensitivity in squamous cell carcinomas of the head and neck. Cancer Res. 1999;59(8):1935-1940.

20. Saleh MN, Raisch KP, Stackhouse MA, et al. Combined modality therapy of A431 human epidermoid cancer using anti-EGFr antibody C225 and radiation. Cancer Biother Radiopharm. 1999;14(6):451-463.

21. Zhang N, Erjala K, Kulmala J, et al. Concurrent cetuximab, cisplatin, and radiation for squamous cell carcinoma of the head and neck in vitro. Radiother Oncol. 2009;92(3):388-392.

22. Fan Z, Baselga J, Masui H, Mendelsohn J. Antitumor effect of antiepidermal growth factor receptor monoclonal antibodies plus cisdiamminedichloroplatinum on well established A431 cell xenografts. Cancer Res. 1993;53(19):4637-4642.

23. Dirks NL, Nolting A, Kovar A, Meibohm B. Population pharmacokinetics of cetuximab in patients with squamous cell carcinoma of the head and neck. J Clin Pharmacol. 2008;48(3):267-278.

24. Baselga J, Pfister D, Cooper MR, et al. Phase I studies of anti-epidermal growth factor receptor chimeric antibody $\mathrm{C} 225$ alone and in combination with cisplatin. J Clin Oncol. 2000;18(4):904-914. 
25. Shin DM, Donato NJ, Perez-Soler R, et al. Epidermal growth factor receptor-targeted therapy with $\mathrm{C} 225$ and cisplatin in patients with head and neck cancer. Clin Cancer Res. 2001;7(5):1204-1213.

26. Robert F, Ezekiel MP, Spencer SA, et al. Phase I study of anti epidermal growth factor receptor antibody cetuximab in combination with radiation therapy in patients with advanced head and neck cancer. J Clin Oncol. 2001;19(13):3234-3243.

27. Bonner JA, Harari PM, Giralt J, et al. Radiotherapy plus cetuximab for squamous-cell carcinoma of the head and neck. $N$ Engl J Med. 2006; 354(6):567-578.

28. Bonner JA, Harari PM, Giralt J, et al. Radiotherapy plus cetuximab for locoregionally advanced head and neck cancer: 5-year survival data from a phase 3 randomised trial, and relation between cetuximabinduced rash and survival. Lancet Oncol. 2010;11(1):21-28.

29. European Medicines Agency. Erbitux: EPAR - Product Information. London: European Medicines Agency; 2009. Available from: http:// www.ema.europa.eu/docs/en_GB/document_library/EPAR_-_Product_ Information/human/000558/WC500029119.pdf. Accessed January 27, 2013.

30. US Food and Drug Administration. Silver Spring: US Food and Drug Administration. Available from: http://www.accessdata.fda.gov/drugsatfda_docs//label/2004/125084lbl.pdf. Accessed January 27, 2013.

31. Pignon JP, le Maître A, Maillard E, Bourhis J; MACH-NC Collaborative Group. Meta-analysis of chemotherapy in head and neck cancer (MACH-NC): an update on 93 randomised trials and 17,346 patients. Radiother Oncol. 2009;92(1):4-14.

32. Koutcher L, Sherman E, Fury M, et al. Concurrent cisplatin and radiation versus cetuximab and radiation for locally advanced head-and-neck cancer. Int J Radiat Oncol Biol Phys. 2011;81(4):915-922.

33. Walsh L, Gillham C, Dunne M, et al. Toxicity of cetuximab versus cisplatin concurrent with radiotherapy in locally advanced head and neck squamous cell cancer (LAHNSCC). Radiother Oncol. 2011;98(1): $38-41$.

34. Chew A, Hay J, Laskin JJ, Wu J, Ho C. Toxicity in combined modality treatment of HNSCC: Cisplatin versus cetuximab. J Clin Oncol. 2011;29 Suppl:Abstr 5526.

35. Shapiro LQ, Sherman EJ, Koutcher L, et al. Efficacy of concurrent cetuximab (C225) versus 5-fluorouracil/carboplatin (5FU/CBDCA) or cisplatin (CDDP) with intensity-modulated radiation therapy (IMRT) for locally advanced head and neck cancer (LAHNSCC). J Clin Oncol. 2012;30 Suppl:Abstr 5537.

36. Pryor DI, Porceddu SV, Burmeister BH, et al. Enhanced toxicity with concurrent cetuximab and radiotherapy in head and neck cancer. Radiother Oncol. 2009;90(2):172-176.

37. Kao J, Genden EM, Gupta V, et al. Phase 2 trial of concurrent 5-fluorouracil, hydroxyurea, cetuximab, and hyperfractionated intensity-modulated radiation therapy for locally advanced head and neck cancer. Cancer. 2011;117(2):318-326.

38. Merlano M, Occelli M. Review of cetuximab in the treatment of squamous cell carcinoma of the head and neck. Ther Clin Risk Manag. 2007;3(5):871-876.

39. Seiwert TY, Haraf DJ, Cohen EE, et al. A randomized phase II trial of cetuximab-based induction chemotherapy followed by concurrent cetuximab, 5-FU, hydroxyurea, and hyperfractionated radiation (CetuxFHX), or cetuximab, cisplatin, and accelerated radiation with concomitant boost (CetuxPX) in patients with locoregionally advanced head and neck cancer (HNC). J Clin Oncol. 2011;29 Suppl:Abstr 5519.

40. Suntharalingam M, Kwok Y, Goloubeva O, et al. Phase II study evaluating the addition of cetuximab to the concurrent delivery of weekly carboplatin, paclitaxel, and daily radiotherapy for patients with locally advanced squamous cell carcinomas of the head and neck. Int J Radiat Oncol Biol Phys. 2012;82(5):1845-1850.

41. Tong CC, Lau KH, Rivera M, et al. Prognostic significance of p16 in locoregionally advanced head and neck cancer treated with concurrent 5-fluorouracil, hydroxyurea, cetuximab and intensity-modulated radiation therapy. Oncol Rep. 2012;27(5):1580-1586.
42. Merlano M, Russi E, Benasso M, et al. Cisplatin-based chemoradiation plus cetuximab in locally advanced head and neck cancer: a phase II clinical study. Ann Oncol. 2011;22(3):712-717.

43. Argiris A, Karamouzis MV, Smith R, et al. Phase I trial of pemetrexed in combination with cetuximab and concurrent radiotherapy in patients with head and neck cancer. Ann Oncol. 2011;22(11):2482-2488.

44. Licitra L, Bergamini C, Olmi P, Soldatenkova V, Ameryckx S, Russo F. Phase I study of concurrent pemetrexed, cetuximab and radiation therapy with or without cisplatin in patients with locally advanced squamous cell carcinoma of the head and neck. Ann Oncol. 2010;21 Suppl 8:1025.

45. Ang KK, Zhang Q, Rosenthal DI, et al. A randomized phase III trial (RTOG 0522) of concurrent accelerated radiation plus cisplatin with or without cetuximab for stage III-IV head and neck squamous cell carcinomas (HNC). J Clin Oncol. 2011;29 Suppl:Abstr 5500.

46. Mesía R, Rueda A, Vera R, et al. Adjuvant therapy with cetuximab for locally advanced squamous cell carcinoma of the oropharynx: results from a randomized, phase II prospective trial. Ann Oncol. 2013;24(2):448-453.

47. Brizel DM, Vokes EE. Induction chemotherapy: to use or not to use? That is the question. Semin Radiat Oncol. 2009;19(1):11-16.

48. Pointreau Y, Atean I, Fayette J, Calais G, Lefebvre JL. Induction chemotherapy in head and neck cancer: a new paradigm. Anticancer Drugs. 2011;22(7):613-620.

49. Specenier PM, Vermorken JB. Neoadjuvant chemotherapy in head and neck cancer: should it be revisited? Cancer Lett. 2007;256(2):166-177.

50. Vokes EE. Induction chemotherapy for head and neck cancer: recent data. Oncologist. 2010;15 Suppl 3:3-7.

51. Argiris A, Heron DE, Smith RP, et al. Induction docetaxel, cisplatin, and cetuximab followed by concurrent radiotherapy, cisplatin, and cetuximab and maintenance cetuximab in patients with locally advanced head and neck cancer. J Clin Oncol. 2010;28(36):5294-5300.

52. Kies MS, Holsinger FC, Lee JJ, et al. Induction chemotherapy and cetuximab for locally advanced squamous cell carcinoma of the head and neck: results from a phase II prospective trial. J Clin Oncol. 2010; 28(1):8-14.

53. Wanebo H, Ghebremichael MS, Burtness B, et al. Phase II induction cetuximab (C225), paclitaxel (P), and carboplatin (C) followed by chemoradiation with C225, P, C, and RT 68-72 Gy for stage III/IV head and neck squamous cancer: Primary site organ preservation and disease control at 2 years (ECOG E2303). J Clin Oncol. 2010;28(15s): Abstr 5513.

54. Adkins D, Ley J, Trinkaus K, et al. A phase 2 trial of induction nabpaclitaxel and cetuximab given with cisplatin and 5-fluorouracil followed by concurrent cisplatin and radiation for locally advanced squamous cell carcinoma of the head and neck. Cancer. 2013;119(4):766-773.

55. Vermorken JB, Remenar E, van den Weyngaert D, et al. Feasibility of cetuximab plus sequential platinum-based therapy (TPF/CRT) in advanced squamous cell head and neck cancer (SCCHN): a randomized phase II study of the EORTC Head and Neck Cancer Group. Eur Arch Otorhinolaryngol. 2012;269:1311-1410 OP 42 (Abstract).

56. Haddad RI, Tishler RB, Norris C, et al. Phase I study of C-TPF in patients with locally advanced squamous cell carcinoma of the head and neck. J Clin Oncol. 2009;27(27):4448-4453.

57. Jordan W, Wildfang I, Welkoborsky $\mathrm{H}$, et al. TPF inductionradioimmunochemotherapy for the treatment of advanced head and neck cancer. $J$ Clin Oncol. 2010;28(15s):Abstr 5514.

58. Ghi MG, Paccagnella A, Ferrari D, et al. Cetuximab/radiotherapy $(\mathrm{CET}+\mathrm{RT})$ versus concomitant chemoradiotherapy $(\mathrm{cCHT}+\mathrm{RT})$ with or without induction docetaxel/cisplatin/5-fluorouracil (TPF) in locally advanced head and neck squamous cell carcinoma (LASCCHN): Preliminary results on toxicity of a randomized, $2 \times 2$ factorial, phase II-III study (NCT01086826). J Clin Oncol. 2012;30 Suppl:Abstr 5513.

59. Lefebvre JL, Pointreau Y, Rolland F, et al. Induction chemotherapy followed by either chemoradiotherapy or bioradiotherapy for larynx preservation: The TREMPLIN randomized Phase II study. J Clin Oncol. 2013;31:853-859. 
60. Keil F, Selzer E, Berghold A, et al. Induction chemotherapy with docetaxel, cisplatin and 5-fluorouracil followed by radiotherapy with cetuximab for locally advanced squamous cell carcinoma of the head and neck. Eur J Cancer. 2013;49(2):352-359.

61. Akmansu M, Buyukberber S, Iren S, et al. Cetuximab concomitant with second-line radiation therapy in patients with locally advanced recurrent squamous cell head and neck cancer. Case Rep Oncol. 2010; 3(3):480-488

62. Balermpas P, Hambek M, Seitz O, Rödel C, Weiss C. Combined cetuximab and reirradiation for locoregional recurrent and inoperable squamous cell carcinoma of the head and neck. Strahlenther Onkol. 2009;185(12):775-781.

63. Comet B, Kramar A, Faivre-Pierret M, et al. Salvage stereotactic reirradiation with or without cetuximab for locally recurrent head-andneck cancer: a feasibility study. Int J Radiat Oncol Biol Phys. 2012; 84(1):203-209.

64. Zwicker F, Roeder F, Thieke C, et al. IMRT reirradiation with concurrent cetuximab immunotherapy in recurrent head and neck cancer Strahlenther Onkol. 2011;187(1):32-38.

65. Heron DE, Rwigema JC, Gibson MK, Burton SA, Quinn AE, Ferris RL. Concurrent cetuximab with stereotactic body radiotherapy for recurrent squamous cell carcinoma of the head and neck: a single institution matched case-control study. Am J Clin Oncol. 2011;34(2):165-172.

66. Kies MS, Harris J, Rotman MZ, et al. Phase II randomized trial of postoperative chemoradiation plus cetuximab for high-risk squamous cell carcinoma of the head and neck (RTOG 0234). Int J Radiat Oncol Biol Phys. 2009;75(3):S14-S15.

67. Burtness B, Goldwasser MA, Flood W, Mattar B, Forastiere AA; Eastern Cooperative Oncology Group. Phase III randomized trial of cisplatin plus placebo compared with cisplatin plus cetuximab in metastatic/ recurrent head and neck cancer: an Eastern Cooperative Oncology Group study. J Clin Oncol. 2005;23(24):8646-8654.

68. Vermorken JB, Mesia R, Rivera F, et al. Platinum-based chemotherapy plus cetuximab in head and neck cancer. $N$ Engl J Med. 2008; 359(11):1116-1127.

69. Licitra L, Mesia R, Rivera F, et al. Evaluation of EGFR gene copy number as a predictive biomarker for the efficacy of cetuximab in combination with chemotherapy in the first-line treatment of recurrent and/or metastatic squamous cell carcinoma of the head and neck: EXTREME study. Ann Oncol. 2011;22(5):1078-1087.

70. Specenier P, Vermorken JB. The role of taxanes and targeted therapies in locally advanced head and neck cancer. Curr Opin Oncol. 2007;19(3):195-201.

71. Hitt R, Irigoyen A, Cortes-Funes H, Grau JJ, García-Sáenz JA, Cruz-Hernandez JJ; Spanish Head and Neck Cancer Cooperative Group (TTCC). Phase II study of the combination of cetuximab and weekly paclitaxel in the first-line treatment of patients with recurrent and/or metastatic squamous cell carcinoma of head and neck. Ann Oncol. 2012;23(4):1016-1022.

72. Guigay J, Fayette J, Dillies AF, et al. Cetuximab, docetaxel, and cisplatin (TPEx) as first-line treatment in patients with recurrent or metastatic (R/M) squamous cell carcinoma of the head and neck (SCCHN): First results of phase II trial GORTEC 2008-2003. J Clin Oncol. 2011;29 Suppl:Abstr 5567.

73. Clark JI, Greene JB, Lau Clark A, Dalal JS, Hofmeister CC. Phase I pilot study of oxaliplatin, infusional 5-FU, and cetuximab in recurrent or metastatic head and neck cancer. Med Oncol. 2013;30(1):358.

74. Vermorken JB, Gauler TC, Stoehlmacher-Williams J, et al. Phase II study of pemetrexed plus cisplatin and cetuximab in advanced squamous cell carcinoma of the head and neck. Ann Oncol. 2012;23:ix334-ix347 1022PD (Abstract).

75. Baselga J, Trigo JM, Bourhis J, et al. Phase II multicenter study of the antiepidermal growth factor receptor monoclonal antibody cetuximab in combination with platinum-based chemotherapy in patients with platinum-refractory metastatic and/or recurrent squamous cell carcinoma of the head and neck. J Clin Oncol. 2005;23(24):5568-5577.
76. Herbst RS, Arquette M, Shin DM, et al. Phase II multicenter study of the epidermal growth factor receptor antibody cetuximab and cisplatin for recurrent and refractory squamous cell carcinoma of the head and neck. J Clin Oncol. 2005;23(24):5578-5587.

77. Vermorken JB, Trigo J, Hitt R, et al. Open-label, uncontrolled, multicenter phase II study to evaluate the efficacy and toxicity of cetuximab as a single agent in patients with recurrent and/or metastatic squamous cell carcinoma of the head and neck who failed to respond to platinumbased therapy. J Clin Oncol. 2007;25(16):2171-2177.

78. Vermorken JB, Herbst RS, Leon X, Amellal N, Baselga J. Overview of the efficacy of cetuximab in recurrent and/or metastatic squamous cell carcinoma of the head and neck in patients who previously failed platinum-based therapies. Cancer. 2008;112(12):2710-2719.

79. León X, Hitt R, Constenla M, et al. A retrospective analysis of the outcome of patients with recurrent and/or metastatic squamous cell carcinoma of the head and neck refractory to a platinum-based chemotherapy. Clin Oncol (R Coll Radiol). 2005;17(6):418-424.

80. Fury MG, Sherman E, Lisa D, et al. A randomized phase ii study of cetuximab every 2 weeks at either 500 or $750 \mathrm{mg} / \mathrm{m}^{2}$ for patients with recurrent or metastatic head and neck squamous cell cancer. $J$ Natl Compr Canc Netw. 2012;10(11):1391-1398.

81. Massa E, Dessì M, Gaspardini G, Saba F, Cherchi V, Mantovani G. Phase II study of vinorelbine/cetuximab in patients with recurrent/ metastatic squamous cell carcinoma of the head and neck progressing after at least two chemotherapy regimens. Oral Oncol. 2010;46(11):818-821.

82. Knoedler MK, Gauler T, Matzdorff A, et al. Multicenter phase II study of cetuximab plus docetaxel in 84 patients with recurrent or metastatic, platinum-pretreated SCCHN. J Clin Oncol. 2009;27(15s): Abstr 6048.

83. Tinhofer I, Klinghammer K, Weichert W, et al. Expression of amphiregulin and EGFRvIII affect outcome of patients with squamous cell carcinoma of the head and neck receiving cetuximab-docetaxel treatment. Clin Cancer Res. 2011;17(15):5197-5204.

84. Argiris A, Duffy AG, Kummar S, et al. Early tumor progression associated with enhanced EGFR signaling with bortezomib, cetuximab, and radiotherapy for head and neck cancer. Clin Cancer Res. 2011; 17(17):5755-5764.

85. Argiris A, Kotsakis AP, Hoang T, et al. Cetuximab and bevacizumab: preclinical data and phase II trial in recurrent or metastatic squamous cell carcinoma of the head and neck. Ann Oncol. 2013;24(1):220-225.

86. StatBite: Radiation therapy plus cetuximab: skin reactions from 71 head and neck cancer patients from 11 institutions in Europe. J Natl Cancer Inst. 2010;102(2):75.

87. Azad A. Severe cutaneous toxicity following treatment with radiotherapy and cetuximab: a case report. Cases J. 2009;2(1):25.

88. Billan S, Abdah-Bortnyak R, Kuten A. Severe desquamation with skin necrosis: a distinct pattern of skin toxicity secondary to head and neck irradiation with concomitant cetuximab. Isr Med Assoc J. 2008; 10(3):247

89. Bölke E, Gerber PA, Lammering G, et al. Development and management of severe cutaneous side effects in head-and-neck cancer patients during concurrent radiotherapy and cetuximab. Strahlenther Onkol. 2008;184(2):105-110.

90. Budach W, Bölke E, Homey B. Severe cutaneous reaction during radiation therapy with concurrent cetuximab. $N$ Engl J Med. 2007; 357(5):514-515.

91. Chan A, Teoh D, Sanghera P, Hartley A. Radiotherapy compliance is maintained with hypofractionation and concurrent cetuximab in locally advanced head and neck cancer. Radiother Oncol. 2009;93(3):654.

92. Giro C, Berger B, Bölke E, et al. High rate of severe radiation dermatitis during radiation therapy with concurrent cetuximab in head and neck cancer: results of a survey in EORTC institutes. Radiother Oncol. 2009;90(2):166-171.

93. Koutcher LD, Wolden S, Lee N. Severe radiation dermatitis in patients with locally advanced head and neck cancer treated with concurrent radiation and cetuximab. Am J Clin Oncol. 2009;32(5):472-476. 
94. Mydin AR, Armstrong JG. Acneiform rash secondary to cetuximab plus head and neck radiotherapy. Radiother Oncol. 2007;85(1):171.

95. Studer G, Brown M, Salgueiro EB, et al. Grade 3/4 dermatitis in head and neck cancer patients treated with concurrent cetuximab and IMRT. Int J Radiat Oncol Biol Phys. 2011;81(1):110-117.

96. Vano-Galvan S, de las Heras E, Harto A, Jaen P. Severe cutaneous toxicity during concomitant radiotherapy and cetuximab treatment of head and neck cancer. Eur J Dermatol. 2008;18(4):471-472.

97. Waris W, Naik S, Idrees I, et al. Severe cutaneous reaction to cetuximab with possible association with the use of over-the-counter skin care products in a patient with oropharyngeal cancer. Cutan Ocul Toxicol. 2009;28(1):41-44.

98. Langendijk JA, Oosting SF. Grading system and management guidelines for dermatitis induced by head and neck radiotherapy plus cetuximab: clinical validation required. Ann Oncol. 2011;22(10): 2157-2159.

99. Bernier J, Bonner J, Vermorken JB, et al. Consensus guidelines for the management of radiation dermatitis and coexisting acne-like rash in patients receiving radiotherapy plus EGFR inhibitors for the treatment of squamous cell carcinoma of the head and neck. Ann Oncol. 2008;19(1):142-149.

100. Bernier J, Russi EG, Homey B, et al. Management of radiation dermatitis in patients receiving cetuximab and radiotherapy for locally advanced squamous cell carcinoma of the head and neck: proposals for a revised grading system and consensus management guidelines. Ann Oncol. 2011;22(10):2191-2200.

101. Grandvuillemin A, Disson-Dautriche A, Miremont-Salamé G, Fourrier-Reglat A, Sgro C; The Reseau des Centres Regionaux de Pharmacovigilance Francais. Cetuximab infusion reactions: French pharmacovigilance database analysis. J Oncol Pharm Pract. Epub November 15, 2012.
102. Hansen NL, Chandiramani DV, Morse MA, Wei D, Hedrick NE, Hansen RA. Incidence and predictors of cetuximab hypersensitivity reactions in a North Carolina academic medical center. J Oncol Pharm Pract. 2011;17(2):125-130.

103. Mesía R, Rivera F, Kawecki A, et al. Quality of life of patients receiving platinum-based chemotherapy plus cetuximab first line for recurrent and/or metastatic squamous cell carcinoma of the head and neck. Ann Oncol. 2010;21(10):1967-1973.

104. Curran D, Giralt J, Harari PM, et al. Quality of life in head and neck cancer patients after treatment with high-dose radiotherapy alone or in combination with cetuximab. J Clin Oncol. 2007;25(16): 2191-2197.

105. Griffin S, Walker S, Sculpher M, et al. Cetuximab plus radiotherapy for the treatment of locally advanced squamous cell carcinoma of the head and neck. Health Technol Assess. 2009;13 Suppl 1:49-54.

106. Brown B, Diamantopoulos A, Bernier J, et al. An economic evaluation of cetuximab combined with radiotherapy for patients with locally advanced head and neck cancer in Belgium, France, Italy, Switzerland, and the United Kingdom. Value Health. 2008;11(5): 791-799.

107. Chan AL, Leung HW, Huang SF. Cost effectiveness of cetuximab concurrent with radiotherapy for patients with locally advanced head and neck cancer in Taiwan: a decision-tree analysis. Clin Drug Investig. 2011;31(10):717-726.

108. Greenhalgh J, Bagust A, Boland A, et al. Cetuximab for the treatment of recurrent and/or metastatic squamous cell carcinoma of the head and neck. Health Technol Assess. 2009;13 Suppl 3:49-54.

109. Hannouf MB, Sehgal C, Cao JQ, Mocanu JD, Winquist E, Zaric GS. Cost-effectiveness of adding cetuximab to platinum-based chemotherapy for first-line treatment of recurrent or metastatic head and neck cancer. PLoS One. 2012;7(6):e38557.
Biologics: Targets \& Therapy

\section{Publish your work in this journal}

Biologics: Targets \& Therapy is an international, peer-reviewed journal focusing on the patho-physiological rationale for and clinical application of Biologic agents in the management of autoimmune diseases, cancers or other pathologies where a molecular target can be identified. This journal is indexed on PubMed Central, CAS, EMBase, Scopus

\section{Dovepress}

and the Elsevier Bibliographic databases. The manuscript management system is completely online and includes a very quick and fair peerreview system, which is all easy to use. Visit http://www.dovepress com/testimonials.php to read real quotes from published authors. 